\title{
O JUIZ BRASILEIRO E O DEVER DE REALIZAR O CONTROLE DE CONVENCIONALIDADE
}

\author{
Cleber Lúcio de Almeida* \\ Sanzer Caldas Moutinho** \\ Wânia Guimarães Rabêllo de Almeida ${ }^{* * *}$
}

RESUMO. A Constituição da República de 1988 atribui força normativa aos tratados sobre direitos humanos, fato que traz à luz a questão relativa ao controle de convencionalidade das normas internas. $\mathrm{O}$ artigo demonstra, adotando como metodologia a revisão bibliográfica, que o juiz tem o dever de realizar, inclusive de ofício, o controle de convencionalidade das normas internas, temática que ganha especial relevância em momento no qual a força normativa dos tratados vem sendo colocada em xeque pelo próprio legislador, como se deu no contexto da reforma trabalhista brasileira, por exemplo.

PALAVRAS-CHAVE. Tratados sobre direitos humanos; controle de convencionalidade; dever do juiz.

\section{THE BRAZILIAN JUDGE AND THE DUTY TO CARRY OUT CONVENTIONALITY CONTROL}

\begin{abstract}
The Constitution of the Republic of 1988 attributes normative force to treaties on human rights, a fact that brings to light the issue related to the conventionality control of internal norms. The article demonstrates, adopting the bibliographic review as a methodology, that the judge has the duty to carry out, including ex officio, the control of conventionality of internal rules, a theme that gains special relevance at a time when the normative force of treaties has been placed in check by the legislator himself, as in the context of the Brazilian labor reform, for example.
\end{abstract}

KEY WORDS. Human rights treaties; conventionality control; duty of the judge.

\section{INTRODUÇÃO}

\footnotetext{
* Pós-doutor em Direito pela Universidad Nacional de Córdoba/ARG. Doutor em Direito pela Universidade Federal de Minas Gerais. Professor dos cursos de graduação e pós-graduação (mestrado e doutorado) da Pontifícia Universidade Católica de Minas Gerais; cleberlucioalmeida@gmail.com. Rua Goitacazes, n. 145, Barro Preto, Belo Horizonte/MG, CEP 30.190.055.

** Mestrando do Programa de Pós-graduação em Direito da Pontifícia Universidade Católica de Minas Gerais, orientado pelo professor Cléber Lúcio de Almeida. Bolsista da CAPES. Pós-graduado (lato sensu) em Direito do Trabalho pelo IEC-Puc Minas. sanzercaldas@msn.com. Av. Raja Gabaglia, 4.859, sl. 231, Belo Horizonte/MG, CEP 30.360-670.

*** Pós-doutora em Ciências Sociales, Humanidades y Artes pela Universidad Nacional de Córdoba/ARG. Doutora e Mestre em Direito Privado pela Puc-Minas. Professora de Direitos Humanos e Antropologia, Sociologia e Etnias e Coordenadora do Núcleo da Diversidade da Faculdade Milton Campos; waniarabello.adv@gmail.com. Rua Guajajara, n. 880 - sala 1306 - Centro - Belo Horizonte/MG, CEP 30170080 .
} 
A Constituição da República de 1988 atribui força normativa aos tratados sobre direitos humanos (art. $5^{\circ}, \S 2^{\circ}$ ), ${ }^{1}$ promovendo, com isto, a abertura do ordenamento jurídico brasileiro ao Direito Internacional dos Direitos Humanos, fato que traz à luz a questão relativa ao controle de convencionalidade das normas internas, tendo o artigo como objetivo demonstrar que o juiz tem o dever de realizar, inclusive de ofício, este controle.

A temática explorada no artigo ganha especial relevância em momento no qual a força normativa dos tratados é colocada em xeque pelo próprio legislador, como se deu no contexto da reforma trabalhista brasileira, por exemplo.

Com efeito, a Lei n. 13.467/2017, que faz parte da reforma trabalhista, incluiu na Consolidação das Leis do Trabalho (CLT) norma segundo a qual aplicam-se à reparação de danos de natureza extrapatrimonial decorrente da relação de trabalho "apenas" os dispositivos constantes da CLT (art. 223-A), solução que foi adotada para impor a tarifação do valor da reparação de tais danos, que foi também estabelecida pela citada lei, por meio da inclusão, na CLT, do art. 223-G, $\S 1^{\circ}$.

Ocorre que a reparação integral dos danos extrapatrimoniais é assegurada pelo art. $1^{\circ}$ da Convenção n. 19 da Organização Internacional do Trabalho, pelos arts. 15, n. 2, e 16, n. 5, da Convenção n. 169 da Organização Internacional do Trabalho e pelos arts. 9º n. 5, e 14, n. 6, do Pacto Internacional sobre Direitos Civis e Políticos e pelo art. 63, n. 1, da Convenção Americana sobre Direitos Humanos.

Em suma, a reparação integral dos danos extrapatrimoniais constitui um direito humano, que foi flagrantemente violado pelos arts. 223-A e 223-G, $\$ 1^{\circ}$, da CLT. ${ }^{2}$

Este é apenas um exemplo de desrespeito a tratados sobre direitos humanos, visto que tem sido reiteradamente sustentado por algumas autoridades brasileiras, no contexto do debate sobre o distanciamento social em razão da Covid-19, que a liberdade individual se sobrepõe à vida, o que coloca em segundo plano o respeito ao direito humano à vida.

\footnotetext{
${ }^{1}$ A expressão "tratado" é utilizada em sentido amplo, ou seja, compreendendo tratado em sentido estrito, convenções, pactos e acordos.

${ }^{2}$ A hipótese é, também, de violação de direito fundamental, como tal como reconhecido no art. $5^{\circ}, \mathrm{V}, \mathrm{X}$ e XXV, da Constituição, manifestando-se, neste particular, inclusive, inegável discriminação dos(as) trabalhadores(as), na medida em que, além da Constituição, o Código Civil, assegura a reparação em valor proporcional ao dano experimentado pela vítima (art. 944), ou seja, um direito assegurado a todas as pessoas vítimas de danos extrapatrimonial foi negado aos trabalhadores.
} 
Aliás, como consta do editorial do Boletim n. 10 Direitos na Pandemia: mapeamento e análises das normas jurídicas de resposta à Covid-19 no Brasil, o direito brasileiro tem servido tanto como escudo voltado à proteção dos direitos fundamentais como "espada que os ataca e ameaça, pois normas e decisões judiciais têm servido a ambos os papéis" (CONECTAS DIREITOS HUMANOS; CEPEDISA, 2021, p. 2).

O artigo é dividido em três partes, às quais seguem anotações conclusivas.

A primeira analisa a força normativa dos tratados sobre direitos humanos e a sua hierarquia no ordenamento jurídico brasileiro, na perspectiva de que o controle de convencionalidade depende do reconhecimento de que as normas de Direito Internacional dos Direitos Humanos gozam de posição diferenciada no ordenamento jurídico brasileiro.

A segunda parte trata do controle de convencionalidade nas suas várias dimensões, o que envolve a definição dos seus efeitos.

A terceira parte versa sobre o controle de convencionalidade como dever do juiz brasileiro, observando-se que, quando se fala em “juiz", tem-se em vista todos os órgãos do Poder Judiciário.

A presente pesquisa adota como metodologia a análise bibliográfica.

\section{A FORÇA NORMATIVA DOS TRATADOS SOBRE DIREITOS HUMANOS DE QUE O BRASIL SEJA PARTE E SUA HIERARQUIA NO ORDENAMENTO JURÍDICO BRASILEIRO}

A Constituição da República adotou como princípio da República a dignidade da pessoa humana (art. $1^{\circ}$, III).

Caminhando um pouco mais e por conta da adoção do citado princípio, a Constituição da República atribuiu força normativa aos tratados sobre direitos humanos de que o Brasil seja signatário (art. $5^{\circ}, \S 2^{\circ}$ e $\S 3^{\circ}$ ).

A Constituição não parou por aí, na medida em que também adotou o princípio da prevalência dos direitos humanos (art. 4º, II), o que está, inclusive, em harmonia com o art. 29 
da Convenção Americana de Direitos Humanos, que impõe, na hipótese de confronto normativo, a primazia da norma que se revele mais favorável à pessoa humana.

Portanto, os tratados sobre direitos humanos ratificados pelo Brasil possuem força normativa, condição em que obrigam tanto os poderes públicos quanto os particulares, valendo lembrar que direitos humanos não dizem respeito apenas à relação da pessoa com o Estado.

Definido que os tratados sobre direitos humanos ratificados pelo Brasil possuem força normativa, resta verificar a sua hierarquia na ordem jurídica brasileira, na medida em que o controle de convencionalidade tem em vista a possibilidade da prevalência de uma norma que compõe o Direito Internacional dos Direitos Humanos sobre normas internas.

Para tanto, cumpre assinalar que, como decorre do art. $5^{\circ}$, $\S \S 2^{\circ}$ e $3^{\circ}$, da Constituição, os tratados podem ser divididos em três grupos: a) tratados comuns, ou seja, que não versam sobre direitos humanos; b) tratados sobre direitos humanos aprovados sem adoção de quórum especial; c) tratados sobre direitos humanos aprovados com a adoção de quórum especial.

Os tratados comuns são inseridos no ordenamento jurídico brasileiro como equivalentes às leis ordinárias federais, o que se deve ao fato do art. 102, III, b, da Constituição submetê-los a controle de constitucionalidade, assim como ao fato de o art. 105, III, a, da Constituição definir o recurso especial como o apropriado para a impugnação de decisões que os contrariem ou lhes neguem vigência.

A propósito da hierarquia dos tratados, o Supremo Tribunal Federal (STF), nos autos do Habeas Corpus (HC) 72.131/RJ, firmou o entendimento de que:

É pacífico na jurisprudência desta Corte que os tratados internacionais ingressam em nosso ordenamento jurídico tão somente com força de lei ordinária (BRASIL, STF, HC 72.131/RJ, 2003).

Este ponto de vista não foi acolhido por parte da doutrina, ao argumento de que o $\S 2^{\circ}$, do art. $5^{\circ}$, da Constituição, ao dispor que "os direitos e garantias expressos nesta Constituição não excluem outros decorrentes do regime e dos princípios por ela adotados, ou dos tratados 
internacionais em que a República Federativa do Brasil seja parte", autoriza afirmar que estes tratados possuem hierarquia de norma constitucional. (BRASIL, 1988).

Contudo, a Emenda Constitucional n. 45/2004, procurando resolver a questão, inseriu o $\S 3^{\circ}$ no art. $5^{\circ}$, da Constituição, estabelecido que "os tratados e convenções internacionais sobre direitos humanos que forem aprovados, em cada Casa do Congresso Nacional, em dois turnos, por três quintos dos votos dos respectivos membros, serão equivalentes às emendas constitucionais". (BRASIL, 2004).

A um primeiro olhar, portanto, somente os tratados aprovados, em cada Casa do Congresso Nacional, em dois turnos, por três quintos dos votos dos respectivos membros, é que terão o status de norma constitucional.

Chamado a examinar a questão sobre o prisma deste novo dispositivo constitucional, o STF decidiu que os tratados sobre direitos humanos que não fossem aprovados com o quórum definido em tal dispositivo teriam o status de norma infraconstitucional, mas supralegal.

É o que se vê da decisão proferida pelo STF nos autos do Recurso Extraordinário (RE) 466.343-1/SP, que consagra a teoria do duplo status dos tratados e convenções sobre direitos humanos: a) natureza constitucional, para aqueles aprovados pelo rito do art. $5^{\circ}, \S 3^{\circ}$, b) natureza supralegal, mas infraconstitucional, para aqueles não aprovados pelo rito do art. $5^{\circ}, \S$ $3^{\circ}$.

Com efeito, como consta da ementa do acórdão relativo ao julgamento do RE 466.343-1/SP:

[...] diante do inequívoco caráter especial dos tratados internacionais que cuidam da proteção dos direitos humanos, não é difícil entender que a sua internalização no ordenamento jurídico, por meio do procedimento de ratificação previsto na CF/1988, tem o condão de paralisar a eficácia jurídica de toda e qualquer disciplina normativa infraconstitucional com ela conflitante. Nesse sentido, é possível concluir que, diante da supremacia da $\mathrm{CF} / 1988$ sobre os atos normativos internacionais, a previsão constitucional da prisão civil do depositário infiel (art. $5^{\circ}$, LXVII) não foi revogada [...], mas deixou de ter aplicabilidade diante do efeito paralisante desses tratados em relação à legislação infraconstitucional que disciplina a matéria [...]. Tendo em vista o caráter supralegal desses diplomas normativos internacionais, a legislação infraconstitucional posterior que com eles seja conflitante também tem sua eficácia paralisada. (...) Enfim, desde a adesão do Brasil, no ano de 1992, ao PIDCP (art. 11) e à CADH - Pacto de São José da Costa Rica (art. $\left.7^{\circ}, 7\right)$, não há base legal para aplicação da parte final do art. 5, LXVII, da CF/1988, ou seja, para a prisão civil do depositário infiel. (BRASIL, STF, RE 466.343-1/SP, 2008). 
Digno de registro, ainda, a decisão proferida pelo STF nos autos do Habeas Corpus (HC) $96.772 / \mathrm{SP}$ :

"HABEAS CORPUS" - PRISÃO CIVIL - DEPOSITÁRIO JUDICIAL REVOGAÇÃO DA SÚMULA 619/STF - A QUESTÃO DA INFIDELIDADE DEPOSITÂRIA - CONVENÇÃO AMERICANA DE DIREITOS HUMANOS (ARTIGO $7^{\circ}$, n. 7) - NATUREZA CONSTITUCIONAL OU CARÁTER DE SUPRALEGALIDADE DOS TRATADOS INTERNACIONAIS DE DIREITOS HUMANOS? - PEDIDO DEFERIDO. ILEGITIMIDADE JURÍDICA DA DECRETAÇÃO DA PRISÃO CIVIL DO DEPOSITÁRIO INFIEL, AINDA QUE SE CUIDE DE DEPOSITÁRIO JUDICIAL. - Não mais subsiste, no sistema normativo brasileiro, a prisão civil por infidelidade depositária, independentemente da modalidade de depósito, trate-se de depósito voluntário (convencional) ou cuidese de depósito necessário, como o é o depósito judicial. Precedentes. Revogação da Súmula 619/STF. TRATADOS INTERNACIONAIS DE DIREITOS HUMANOS: AS SUAS RELAÇÕES COM O DIREITO INTERNO BRASILEIRO E A QUESTÃO DE SUÁ POSIÇÃO HIERÁRQUICA. - A Convenção Americana sobre Direitos Humanos (Art. $7^{\circ}$, n. 7). Caráter subordinante dos tratados internacionais em matéria de direitos humanos e o sistema de proteção dos direitos básicos da pessoa humana. - Relações entre o direito interno brasileiro e as convenções internacionais de direitos humanos $\left(\mathrm{CF}\right.$, art. $5^{\circ}$ e $\S \S 2^{\circ}$ e $\left.3^{\circ}\right)$. Precedentes. - Posição hierárquica dos tratados internacionais de direitos humanos no ordenamento positivo interno do Brasil: natureza constitucional ou caráter de supralegalidade? Entendimento do Relator, Min. CELSO DE MELLO, que atribui hierarquia constitucional às convenções internacionais em matéria de direitos humanos. A INTERPRETAÇÃO JUDICIAL COMO INSTRUMENTO DE MUTAÇÃO INFORMAL DA CONSTITUIÇÃO. - A questão dos processos informais de mutação constitucional e o papel do Poder Judiciário: a interpretação judicial como instrumento juridicamente idôneo de mudança informal da Constituição. A legitimidade da adequação, mediante interpretação do Poder Judiciário, da própria Constituição da República, se e quando imperioso compatibilizá-la, mediante exegese atualizadora, com as novas exigências, necessidades e transformações resultantes dos processos sociais, econômicos e políticos que caracterizam, em seus múltiplos e complexos aspectos, a sociedade contemporânea. HERMENÊUTICA E DIREITOS HUMANOS: A NORMA MAIS FAVORÁVEL COMO CRITÉRIO QUE DEVE REGER A INTERPRETAÇÃO DO PODER JUDICIÁRIO. - Os magistrados e Tribunais, no exercício de sua atividade interpretativa, especialmente no âmbito dos tratados internacionais de direitos humanos, devem observar um princípio hermenêutico básico (tal como aquele proclamado no Artigo 29 da Convenção Americana de Direitos Humanos), consistente em atribuir primazia à norma que se revele mais favorável à pessoa humana, em ordem a dispensar-lhe a mais ampla proteção jurídica. - O Poder Judiciário, nesse processo hermenêutico que prestigia o critério da norma mais favorável (que tanto pode ser aquela prevista no tratado internacional como a que se acha positivada no próprio direito interno do Estado), deverá extrair a máxima eficácia das declarações internacionais e das proclamações constitucionais de direitos, como forma de viabilizar o acesso dos indivíduos e dos grupos sociais, notadamente os mais vulneráveis, a sistemas institucionalizados de proteção aos direitos fundamentais da pessoa humana, sob pena de a liberdade, a tolerância e o respeito à alteridade humana tornarem-se palavras vãs. - Aplicação, ao caso, do Artigo $7^{\circ}$, n. 7, c/c o Artigo 29, ambos da Convenção Americana de Direitos Humanos (Pacto de São José da Costa Rica): um caso típico de primazia da regra mais favorável à proteção efetiva do ser humano. (BRASIL, STF, HC 96.772/SP, 2009). 
Mais uma vez, parte da doutrina critica este ponto de vista, sob o argumento de que a combinação dos $\S \S 2^{\circ}$ e $3^{\circ}$ do art. $5^{\circ}$ da Constituição permite afirmar que todos os tratados e convenções sobre direitos humanos são materialmente constitucionais, ao passo que, aqueles aprovados observando o rito estipulado no $\S 3^{\circ}$, são material e formalmente constitucionais.

É este o posicionamento de Flávia Piovesan:

Vale dizer, com o advento do $\$ 3^{\circ}$ do art. $5^{\circ}$ surgem duas categorias de tratados internacionais de proteção de direitos humanos: a) os materialmente constitucionais; e b) os material e formalmente constitucionais [...] todos os tratados internacionais de direitos humanos são materialmente constitucionais, por força do $\S 2^{\circ}$ do art. $5^{\circ}$. Para além de serem materialmente constitucionais, poderão, a partir do $\S 3^{\circ}$ do mesmo dispositivo, acrescer a qualidade de formalmente constitucionais, equiparando-se às emendas à Constituição, no âmbito formal. (PIOVESAN, 2013, p. 145).

No mesmo sentido, se posiciona Valério de Oliveira Mazzuoli:

Assim, o que se quer dizer é que o regime material (menos amplo) dos tratados de direitos humanos não pode ser confundido com o regime formal (mais amplo) que esses mesmos tratados podem ter, se aprovados pela maioria qualificada estabelecida no art. $5^{\circ}, \S 3^{\circ}$. Perceba-se que, neste último caso, o tratado assim aprovado será, além de materialmente constitucional, também formalmente constitucional. Assim, fazendo-se uma interpretação sistemática do texto constitucional em vigor, à luz dos princípios constitucionais e internacionais de garantismo jurídico e de proteção à dignidade humana, chega-se à seguinte conclusão: o que o texto constitucional reformado pretendeu dizer é que esses tratados de direitos humanos ratificados pelo Brasil, que já têm status de norma constitucional, nos termos do $\$ 2^{\circ}$ do art. $5^{\circ}$, poderão ainda ser formalmente constitucionais (ou seja, ser equivalentes às emendas constitucionais), desde que, a qualquer momento, depois de sua entrada em vigor, sejam aprovados pelo quórum do $\S 3^{\circ}$ do art. $5^{\circ}$ da Constituição. (MAZZUOLI, 2016, p. 218-219).

Mesmo no STF não existe consenso sobre a questão, como decorre da decisão proferida nos autos do Habeas Corpus (HC) 96.772/SP, que registra divergência do Ministro Celso Mello, que foi por ele reiterada no julgamento do Habeas Corpus (HC) 91.361-0/SP. Nestas duas ocasiões, o Ministro Celso Mello atribui aos tratados e convenções sobre direitos humanos a natureza constitucional.

Com efeito, no julgamento deste segundo HC, o Ministro Celso Melo pontuou que: 
$\mathrm{O} \S 2^{\circ}$ do art. $5^{\circ}$ da Constituição - verdadeira cláusula geral de recepção - autoriza o reconhecimento de que os tratados internacionais de direitos humanos possuem hierarquia constitucional, em face da relevantíssima circunstância de que viabilizam a incorporação ao catálogo constitucional de direitos e garantias individuais, de outras prerrogativas e liberdades fundamentais, que passam a integrar, subsumindose no seu conceito, o conjunto normativo configurador do bloco de constitucionalidade. (BRASIL, STF, HC 91.361-0/SP, 2009).

Consoante asseverou o Ministro Celso Mello, a atribuição de hierarquia constitucional aos tratados e convenções sobre direitos humanos viabiliza o acesso dos indivíduos e grupos sociais, notadamente os mais vulneráveis, a sistemas institucionalizados de proteção aos direitos fundamentais da pessoa humana, sob pena de a liberdade, a tolerância e o respeito à alteridade humana tornarem-se palavras vãs.

A questão relativa à hierarquia dos tratados e convenções sobre direitos humanos foi examinada pela Corte Interamericana, no caso "A última tentação de Cristo", no qual decidiu que o Chile deveria alterar a sua Constituição, por estar em desconformidade com a Convenção Americana de Direitos Humanos.

Consta da citada decisão, neste sentido, que:

[...] 72. Esta Corte entende que a responsabilidade internacional do Estado pode gerar por atos ou omissões de qualquer poder ou órgão deste, independentemente de sua hierarquia, que violem a Convenção Americana. É dizer, todo ato ou omissão, imputável ao Estado, em violação das normas do Direito Internacional dos Direitos Humanos, compromete a responsabilidade internacional do Estado. No presente caso esta foi gerada em virtude de que o artigo 19, número 12 da Constituição estabelece a censura prévia na produção cinematográfica e, por outro tanto, determina aos atos dos Poderes Executivo, Legislativo e Judicial. (...) 85. A Corte tem assinalado que o dever geral do Estado, estabelecido no artigo 2 da Convenção, inclui a adoção de medidas para suprimir as normas e práticas de qualquer natureza que impliquem uma violação às garantias previstas na Convenção, assim como a expedição de normas e o desenvolvimento de práticas levando à observância efetiva de ditas garantias. (...) 88. No presente caso, ao manter a censura cinematográfica no ordenamento jurídico chileno (artigo 19 número 12 da Constituição Política e Decreto Lei número 679) o Estado está descumprindo com o dever de adequar seu direito interno à Convenção de modo a fazer efetivos os direitos consagrados na mesma, como o estabelecem os artigos 2 e 1.1 da Convenção. (CIDH, 2001, p. 26)

Assim, para a Corte Interamericana de Direitos Humanos, as normas internacionais de direitos humanos possuem o "status" supraconstitucional. 
A nosso juízo, o art. $5^{\circ}, \S 3^{\circ}$, da Constituição deve ser interpretado em sintonia com o art. $4^{\circ}$, II, também da Constituição, que adota o princípio da prevalência dos direitos humanos ou "princípio pro persona".

Com efeito, ao adotar o citado princípio, a Constituição deixa claro que nenhuma norma interna, seja constitucional ou infraconstitucional, pode violar tratado sobre direitos humanos, o que implica atribuir-lhes hierarquia supraconstitucional. A hipótese é de princípio adotado constitucionalmente, o que significa que o Estado abdicou, neste particular, de sua soberania, não como fim em si mesmo, mas em favor da proteção e promoção da dignidade da pessoa humana.

Ademais, o Estado tem a obrigação de adequar o seu regime jurídico aos tratados e convenções sobre direitos humanos, o que implica obrigação de alterar a sua Constituição, para adequá-la aos tratados e convenções sobre direitos humanos de que seja parte.

Tal obrigação é imposta aos Estados, de forma expressa, pelo art. 27 da Convenção de Viena sobre o Direito dos Tratados, segundo o qual o Estado não pode invocar as disposições do seu direito interno para justificar o inadimplemento de um tratado, prevendo esta Convenção, ainda, que os tratados obrigam as partes (art. $2^{\circ}$ ) e o Estado é obrigado a abster-se da prática de atos que frustrem o objeto e a finalidade de um tratado (artigo 18), pela Declaração Universal dos Direitos Humanos (art. 30), pelo Pacto Internacional dos Direitos Econômicos, Sociais e Culturais (artigo $2^{\circ}$ ), Convenção Americana sobre Direitos Humanos (arts. $1^{\circ}$, n. 1 , e $2^{\circ}$, n. 1), pelo Protocolo Adicional à Convenção Americana sobre Direitos Humanos em Matéria de Direitos Econômicos, Sociais e Culturais (artigos $1^{\circ}$ e $2^{\circ}$ ) e pela Declaração sobre o Direito ao Desenvolvimento (art. $5^{\circ}$ ).

Note-se, inclusive, que, consoante o art. 13 do CPC, no confronto entre "normas processuais brasileiras" e disposições especificas de tratados e convenções, estas é que devem prevalecer, observando-se que "normas processuais brasileiras" são tanto as de status constitucional (devido processo constitucional), como infraconstitucional (devido processo legal), o que indica que deve prevalecer, mesmo no confronto com a Constituição, a norma mais favorável à pessoa humana, como decorre, consoante já assinalado, do art. $4^{\circ}$, II, da Constituição. 
Acrescente-se que os tratados e convenções sobre direitos humanos atuam como verdadeiras metaregras, que impõem parâmetros e limites para o Estado, o que inclui o poder constituinte por ele instituído.

Ademais, as normas de Direito Internacional das quais fazem parte o Brasil a este impõe o dever de promover a progressiva melhoria das condições sociais das pessoas humanas, por meio da maior efetividade possível das normas que os reconhecem.

Neste sentido:

a) na Convenção Americana sobre Direitos Humanos, cujo art. 26 dispõe que os Estados Partes "se comprometem a adotar providências, tanto a nível interno como mediante a cooperação internacional, especialmente econômica e técnica, para alcançar progressivamente a plena efetividade dos direitos que se derivam das normas econômicas, sociais e sobre educação, ciência e cultura, contidas na Carta da Organização dos Estados Americanos"; (CIDH, 1969).

b) no art. $2^{\circ}$ do Pacto Internacional dos Direitos Econômicos, Sociais e Culturais, conforme o qual cada "Estado Parte se compromete a adotar medidas, tanto em separado como mediante a assistência e a cooperação internacionais, especialmente econômicos e técnicos, até o máximo dos recursos de que disponha, para alcançar progressivamente, por todos os meios apropriados, inclusive em particular a adoção de medidas legislativas, à plena efetividade dos direitos aqui reconhecidos", e no art. 11 do mesmo Pacto, que dispõe: "os Estados Partes no presente Pacto reconhecem o direito de toda pessoa a um nível de vida adequado para si e para sua família, inclusive alimentação, vestuário e habitação adequados e a uma melhora contínua nas condições de existência. Os Estados Partes tomarão medidas apropriadas para assegurar a efetividade deste direito" (ONU, PIDCP, 1966).

Desta obrigação decorre que, quando uma norma de Direito Internacional assegurar direito que não tenha sido constitucionalmente assegurado, a Constituição deve ser alterada, para que seja adaptada ao Direito Internacional.

Trata-se, neste caso, da observância do princípio "pro homine”, segundo o qual a regra prevalente, no caso de conflito normativo, deverá ser aquela que melhor garanta e que menos restrinja a fruição de um direito humano, acrescentando-se, neste particular, o princípio, já referido, da progressividade, segundo o qual os direitos sociais estabelecidos devem ser 
aperfeiçoados, não se admitindo, portanto, o retrocesso, devem ser observados no afastamento da legislação interna que por ventura confronte a norma internacional com maior âmbito protetivo e, também, na inaplicabilidade de norma internacional que estabeleça situação de menor proteção em relação às normas internas.

A lição de Valdete Souto Severo é singular nesse sentido:

\begin{abstract}
A noção de desenvolvimento e melhoria constante das condições sociais como parâmetro para a regulação e a interpretação estatal do ordenamento jurídico constitui uma blindagem da ordem constitucional para garantir que, uma vez obtido determinado grau de realização, os direitos sociais passem a constituir uma garantia institucional e um direito subjetivo (SEVERO, 2019, p. 272).
\end{abstract}

Seja como for, isto é, atribuindo-se aos tratados sobre direitos humanos status constitucional ou supralegal, não há como negar que as normas internas (as infraconstitucionais, se admitida a hierarquia apenas supralegal), devem ser objeto de controle de convencionalidade.

\title{
3 CONTROLE DE CONVENCIONALIDADE: significado e dimensões
}

O controle de convencionalidade constitui uma técnica de confronto normativo, que visa verificar a compatibilidade do Direito interno, da interpretação das normas internas e externas e das omissões do Estado com o Direito Internacional, notadamente do Direito Internacional dos Direitos Humanos.

Mas, o objetivo maior do controle de convencionalidade é a "a proteção de determinados princípios comuns no âmbito nacional e internacional, como a dignidade humana" (ZÜÑIGA, 2013, p. 348-350), ou, dito de outra forma, fazer valer a força normativa dos tratados sobre direitos humanos e, com isto, conferir concretude aos direitos humanos.

O controle de convencionalidade parte da premissa de que, nem tudo que é legal é convencional e que a pessoa humana transcende o Estado (MARITAIN, 1982, p. 79).

O controle de convencionalidade possui várias dimensões, posto que pode dar ensejo à declaração de inconvencionalidade:

a) de norma interna incompatível com norma ou normas de Direito Internacional dos Direitos Humanos (trata-se da inconvencionalidade por ausência de harmonia entre o Direito 
interno e o Direito Internacional dos Direitos Humanos, lembrando que qualquer tratado de que o Brasil seja parte pode ser considerado para efeito de controle de convencionalidade de norma interna, no que diz ao seu conteúdo ou interpretação);

Neste caso, para a solução do caso concreto, deve ser aplicada a norma de direito internacional, como resulta do art. 13 do CPC: a norma interna será aplicada, desde que não exista norma internacional mais benéfica à pessoa humana;

b) da interpretação de uma norma interna (a interpretação de uma norma interna não pode conduzir à violação de um tratado sobre Direitos Humanos ou à negativa de sua vigência) ou externa (a norma externa não pode ser interpretada de forma a negar ou limitar o gozo de direitos por ela assegurados. Trata-se de inconvencionalidade por interpretação);

Neste sentido, cumpre recordar que é vedada a interpretação das normas de Direito Internacional de Direitos Humanos que destrua, suprima ou limite de forma desproporcional o gozo e o exercício de direitos (art. 30 da Declaração Universal dos Direitos Humanos e art. 29 da Convenção Americana de Direitos Humanos).

Sendo apurado que esta obrigação não foi cumprida, deverá ser conferida à norma interna interpretação conforme o dispositivo de tratado que favoreça o gozo de direito humano;

c) de uma omissão do Estado em relação à adaptação do Direito interno ao Direito Internacional dos Direitos Humanos ou à adoção de medidas voltadas à garantia da efetividade de direitos humanos (trata-se de inconvencionalidade por omissão). ${ }^{3}$

No caso de omissão, ao Estado deve reparar os danos decorrentes de sua omissão.

Registre-se que, para definir as dimensões do controle de convencionalidade, foram consideradas as obrigações do Estado perante a comunidade internacional, quais sejam:

a) a obrigação de respeitar significa que o Estado "deve abster-se de adotar medidas que possam dificultar ou impedir" o gozo dos direitos humanos, caracterizando o descumprimento desta obrigação a "derrogação de normas de proteção dos trabalhadores", “limitação ou denegação do acesso aos direitos a 'todas' as pessoas" e criação de dificuldades para o acesso à justiça”;

\footnotetext{
${ }^{3}$ Pode ser submetido a controle de convencionalidade tanto atos quanto omissões do Estado.
} 
b) a obrigação de proteger significa que o Estado deve proteger a pessoa humana "das outras pessoas (físicas ou jurídicas)", em especial quando elas se encontrem frente a elementos agressivos, dentre os quais "interesses econômicos poderosos", o que requer, por exemplo, a adoção de medidas legislativas para "amparar os trabalhadores" contra "práticas trabalhistas danosas", caracterizando descumprimento desta obrigação o "abandono da população às 'leis do mercado', em matéria de salários, por exemplo;

c) a obrigação de realizar constitui gênero, que tem como espécies as obrigações de facilitar (o Estado deve "procurar iniciar atividades com o fim de fortalecer o gozo" dos direitos humanos ou dos "direitos que compõem o direito a um nível de vida adequado"), fazer efetivo (os Estados devem tornar efetivos os direitos quando um indivíduo ou grupo for incapaz, por razões que escapam ao seu controle, de gozá-los, utilizando, para cumprir esta sua obrigação, inclusive "os instrumentos tendentes a realizar uma verdadeira e justa distribuição da riqueza nacional") e proteger (o que significa que o Estado deve "promover, manter e restabelecer a saúde da população”) (GIALDINO, 2003, p. 95-105).

Como já foi asseverado, os juízes não pode "ignorar que todas as normas relativas a direitos humanos, inclusive as normas de princípios, são de aplicação direta e imediata, nos precisos termos do disposto no art. $5^{\circ}, \S 1^{\circ}$, da Constituição Federal” (COMPARATO, on line), ou seja, as obrigações atribuídas ao Estado devem ser por ele cumpridas quando do exercício de todas as suas funções, ou seja, executiva, legislativa e jurisdicional.

\section{CONTROLE DE CONVENCIONALIDADE COMO DEVER DO JUIZ}

Constitui obrigação do Estado brasileiro, inclusive no exercício da função jurisdicional, respeitar e fazer respeitar tratados sobre direitos humanos de que seja signatário.

Desde modo, editada, pelo poder legislativo, uma dada norma, cumpre verificar a sua compatibilidade com o Direito Internacional dos Direitos Humanos.

O controle de convencionalidade pode ser realizado tanto pelos órgãos que compõem o sistema de justiça brasileira (juízes e tribunais), como pela Corte Interamericana de Direitos Humanos, lembrando, quanto a este último aspecto, que, na Opinião Consultiva OC-1/1982, a Corte Interamericana de Direitos Humanos, reconheceu, à luz do art. 64 da Declaração 
Americana de Direitos Humanos, a sua competência para interpretar quaisquer tratados sobre direitos humanos celebrados pelos Estados submetidos à sua jurisdição. (CIDH, 1982).

Não há dúvida de que, sendo provocado, o juiz deverá realizar o controle de convencionalidade das normas internas. É o que resulta, por exemplo, da previsão no sentido de que o Superior Tribunal de Justiça tem competência para julgar recurso especial no qual seja alegada negativa de vigência a tratado.

Mas, o controle de convencionalidade das normas internas constitui um dever do juiz?

A resposta positiva se impõe.

Neste sentido, o CPC estabelece que, ao aplicar o ordenamento jurídico, o juiz deverá resguardar e prover a dignidade da pessoa humana (art. $8^{\circ}$ ).

Resguardar e proteger a dignidade humana implica resguardar e proteger os direitos a ela inerentes, ou seja, os direitos humanos. Isto significa que, se uma norma interna viola um tratado sobre direitos humanos e, com isto, um direito humano, o juiz deve, para resguardar e prover a dignidade humana, afastar a aplicação da norma interna, tenha sido provocado para fazê-lo ou não (o cumprimento de um dever dispensa a provocação do juiz para fazê-lo).

Não é só.

$\mathrm{O}$ art. 13 do $\mathrm{CPC}$ dispõe que a jurisdição será regida pelas normas processuais brasileiras, ressalvadas as disposições específicas previstas em tratados, convenções ou acordo internacionais que o Brasil seja parte.

Assim, a legislação brasileira será aplicada, salvo se existir norma de Direito Internacional específica, o que impõe, por força do princípio da prevalência dos direitos humanos, que a norma interna ceda lugar à norma que reconhecer um direito humano.

Dito de outro modo, somente será respeitada a ressalva que favorece os direitos humanos quando o juiz realizar o confronto da norma interna com a supranacional. Se este confronto não for realizado, o art. 13 do CPC será uma letra morta, ou seja, a ressalva por ele estabelecida não surtirá efeito concreto se o juiz não realizar o confronto do Direito interno com o Direito Internacional dos Direitos Humanos. 
Portanto, o CPC, impõe ao juiz o dever de verificar, de ofício ou mediante provocação, se, no caso concreto, a norma invocada está em harmonia com uma norma de Direito Internacional dos Direitos Humanos, ou seja, o dever de realizar o controle de convencionalidade das normas internas. Isto implica, inclusive, que ao juiz é vedado assumir uma postura passiva quando se trate de desrespeito aos direitos humanos. ${ }^{4}$

Ademais, o dever de controle de convencionalidade decorre do fato de a Constituição impor respeito aos tratados sobre direitos humanos. A Constituição, em suma, impõe aos juízes a obrigação de respeitar e faze respeitar tratados sobre direitos humanos.

A existência deste dever também resulta do art. $4^{\circ}$, II, da Constituição, vez que somente se pode falar em prevalência de norma internacional se ela for confrontada com norma interna.

Ainda na Constituição, inclusive, é previsto que cabe recurso especial quando houver violação ou negativa de vigência a tratado, o que reafirma o que consta dos arts. $8^{\circ}$ e 13 do CPC, ou seja, que o juiz tem o dever de realizar o controle de convencionalidade das normas internas.

A existência do dever de controle de convencionalidade é reconhecido, inclusive, na decisão proferida pela Corte Interamericana de Direitos Humanos no "Caso Almonacid Arrellano y outros vs. Governo do Chile" (considerando n. 124). Nesta oportunidade, a Corte decidiu que "os juízes e tribunais internos estão sujeitos ao império da lei e, por isto, estão obrigados a aplicar as disposições vigentes no ordenamento jurídico. Mas, quando um Estado tiver ratificado um tratado internacional como a Convenção Americana, seus juízes, como parte do aparato do Estado, também estão submetidos a ela, o que os obriga a velar para que os efeitos das disposições da Convenção não sejam prejudicados pela aplicação de leis contrárias ao seu objeto e fim" (CIDH, 2002).

Mas, o controle convencionalidade não se limita, como já foi adiantado, à realização do confronto entre normas.

\footnotetext{
${ }^{4}$ Esta constatação permite afirmar que os deveres do juiz são elencados no art. 139 de forma exemplificativa, observando-se que o inciso VI deste dispositivo impõe ao juiz a adoção de medidas que confiram a maior efetividade aos direitos, o que inclui os direitos humanos, por força dos arts. $8^{\circ}$ e 13 do mesmo CPC.
} 
Com efeito, também a interpretação conferida às normas internas e internacionais deve estar em harmonia com o Direito Internacional dos Direitos Humanos, ou seja, a uma norma interna ou externa não pode ser conferido sentido que afete o exercício de um direito humano.

Acrescente-se que a violação a um tratado de direito humano pode resultar de uma omissão do Estado, quando do tratado resulte a obrigação de adaptar as disposições internas ao Direito Internacional dos Direitos Humanos.

Neste sentido, por exemplo, o Protocolo Adicional à Convenção Americana sobre Direitos Humanos em Matéria de Direitos Econômicos, Sociais e Culturais, estabelece, em seus arts. $1^{\circ}$ e $2^{\circ}$, a obrigação de os Estados adotarem medidas legislativas que garantam a plena efetividade dos direitos nele reconhecidos, o Pacto Internacional dos Direitos Econômicos, Sociais e Culturais impõe aos Estados a obrigação de adotar medidas que visem assegurar, progressivamente, por todos os meios apropriados, o pleno exercício dos direitos nele reconhecidos (art. $2^{\circ}$ ), e a Convenção Americana sobre Direitos Humanos, segundo a qual os Estados têm a obrigação de respeitar os direitos e liberdades nela reconhecidos e garantir o seu livre e pleno exercício ( $\operatorname{art.} 1^{\circ}$, n. 1) e adotar as medidas legislativas ou de outra natureza que forem necessárias para tornar efetivos os direitos e garantias nela previstos (art. $2^{\circ}$, n. 1). Neste caso, dar-se-á a inconvencionalidade por omissão.

Mas, qual é a relevância de chamar a atenção para este dever judicial?

Primeiro, porque, como resulta dos citados comandos constitucionais, legais e supranacionais invocados, o homem se sobrepõe ao Estado, o que exige que se dê concretude aos direitos cujo gozo é considerado o mínimo necessário para uma vida conforme a dignidade humana.

Segundo, porque o princípio da legalidade deve ser considerado em toda a sua complexidade, no sentido de vinculação dos poderes estatais também ao Direito Internacional dos Direitos Humanos, na perspectiva, inclusive, de que nem tudo que é legal é convencional.

Terceiro, porque as obrigações do Estado em relação aos direitos humanos alcançam todas as suas funções, dentre as quais a legislativa e judicial.

Quarto, porque os sistema interamericano de direitos humanos impõe uma nova "maneira de conceber e entender o constitucionalismo atual, a qual nos exige novas posturas 
teóricas e práticas sobre as estruturas de proteção dos direitos humanos no nível nacional e internacional" e sobre as relações entre os sistemas jurídicos, qual seja, o "constitucionalismo multinível", sustentado no "pluralismo constitucional" e no diálogo judicial" (MARTINÉZ, 2017 , p. 38 e 39), o que torna todo juiz um juiz convencional.

Quinto, porque é urgente e indispensável fazer valer os direitos humanos em um país que se encontra entre os dez piores países para os trabalhadores (CSI. Índice Global de los Derechos 2020, p. 6, 25, 37 e 51).

Sexto, porque a Agenda 2030 da ONU para o Desenvolvimento Sustentável, na qual o Brasil participou, considera indispensável o respeito aos direitos humanos, o qual, como dito, constitui um dever do juiz.

Sétimo, porque é necessário assegurar o efeito útil dos tratados (MAUÉS; MAGALHÃES, 2018, p. XI-XII).

Oitavo, porque a realização do controle de convencionalidade é "instituto que serve de instrumento para a aplicação do direito internacional" (MAUÉS; MAGALHÃES, 2018, p. XIV) e, com isto, promover e proteger a dignidade humana, dever que também cabe aos juízes, consoante já foi demonstrado.

Digno de registro que:

O processo de universalização dos direitos humanos permitiu a formação de um sistema internacional de proteção destes direitos. Este sistema é integrado por tratados internacionais de proteção que refletem, sobretudo, a consciência ética contemporânea compartilhada pelos Estados, na medida em que invocam o consenso internacional acerca de temas centrais aos direitos humanos, na busca da salvaguarda de parâmetros protetivos mínimos - do mínimo ético irredutível. Cabe destacar que, até junho de 2006, o Pacto Internacional dos Direitos Civis e Políticos contava com 156 Estados-partes; o Pacto Internacional dos Direitos Econômicos, Sociais e Culturais contava com 141 Estados-partes; a Convenção sobre a Eliminação da Discriminação Racial contava com 170 Estados-partes; a Convenção sobre a Eliminação da Discriminação contra a Mulher contava com 183 Estadospartes e a Convenção sobre os Direitos da Criança apresentava a mais ampla adesão, com 192 Estados-partes. (PIOVESAN, 2011, p. 48).

\section{ANOTAÇÕES CONCLUSIVAS}


O artigo versou sobre o controle de convencionalidade como técnica de confronto normativo, que visa verificar a compatibilidade do Direito interno, da interpretação das normas internas e externas e das omissões do Estado com o Direito Internacional, notadamente do Direito Internacional dos Direitos Humanos.

O artigo demonstra que a ordem jurídica brasileira impõe ao juiz a realização, inclusive, de ofício, do controle de convencionalidade, o que deve alcançar normas infraconstitucionais e constitucionais, observando-se que os arts. $1^{\circ}$, III, $4^{\circ}$, II e $5^{\circ}$, parágrafos $2^{\circ}$ e $3^{\circ}$, da Constituição são normas imperativas, que fundamentam a arquitetura constitucional de prevalência do ser humano.

O controle de constitucionalidade é dever imposto ao juiz visando fazer valer a força normativa dos tratados e convenções sobre direitos humanos, respeitar o princípio da prevalência dos direitos humanos e, principalmente, realizar concretamente os direitos humanos, que são reconhecidos com o objetivo último de promover e proteger a dignidade humana.

A finalidade, portanto, é a constituição sólida de um modelo de desenvolvimento humanitário calcado no valor da pessoa humana em si, que carece de proteção irrestrita.

A imposição deste dever exige que todo juiz seja um juiz convencional, isto é, comprometido com o respeito aos tratados sobre direitos humanos e com a realização concreta dos direitos humanos.

\section{REFERÊNCIAS BIBLIOGRÁFICAS}

BRASIL, Supremo Tribunal Federal (2. Turma). Habeas Corpus 91.361-0/SP. Depositário legal (leiloeiro oficial). A questão da infidelidade depositária. Convenção americana de direitos humanos [...]. Relator: Min. Celso de Mello, 23 set.2008. Diário de Justiça Eletrônico, Brasília, DF, n.25, 05 fev.2009. Disponível em: https://redir.stf.jus.br/paginadorpub/paginador.jsp?docTP=AC\&docID=573717. Acesso em: 14.abr.2021

BRASIL, Supremo Tribunal Federal (2. Turma). Habeas Corpus 96.772/SP. Prisão civil. Depositário judicial. Revogação da súmula 619/STF [...]. Relator: Min. Celso de Mello, 09 jun.2009. Diário de Justiça Eletrônico, Brasília, DF, n.157, 20 ago.2009. Disponível em: https://redir.stf.jus.br/paginadorpub/paginador.jsp?docTP=AC\&docID=601192. Acesso em: 14.abr.2021. 
BRASIL, Supremo Tribunal Federal (plenário). Habeas Corpus 72.131-1/RJ. Alienação fiduciária em garantia. Prisão civil do devedor como depositário infiel [...]. Relator: Min. Marco Aurélio, 23 nov.1995. Diário de Justiça Eletrônico, Brasília, DF, n.21, 01 ago.2003. Disponível em:

https://redir.stf.jus.br/paginadorpub/paginador.jsp?docTP=AC\&docID=73573. Acesso em: 13.abr.2021.

BRASIL, Supremo Tribunal Federal (plenário). Recurso Extraordinário 466.343-1/SP. Prisão civil. Depósito. Depositário infiel. Alienação fiduciária. Decretação da medida coercitiva. Inadmissibilidade absoluta. [...]. Relator: Min. Cezar Peluso, 03 dez.2008. Diário de Justiça Eletrônico, Brasília, DF, n.236, 11 dez.2008. Disponível em:

https://redir.stf.jus.br/paginadorpub/paginador.jsp?docTP=AC\&docID=595444. Acesso em: 13.abr.2021.

BRASIL. [Constituição (1988)]. Constituição da República Federativa do Brasil de 1988. Brasília, DF: Presidência da República, [2020]. Disponível em: http://www.planalto.gov.br/ccivil_03/Constituicao/Constituiçao.htm. Acesso em: 20 abr. 2020.

BRASIL. Emenda Constitucional $\mathbf{n}^{\mathbf{0}} \mathbf{. 4 5}$, de 30 de dezembro de 2004. Altera dispositivos dos arts. $5^{\circ}, 36,52,92,93,95,98,99,102,103,104,105,107,109,111,112,114,115,125$, 126, 127, 128, 129, 134 e 168 da Constituição Federal, e acrescenta os arts. 103-A, 103B, 111-A e 130-A, e dá outras providências. Brasília, DF: Presidência da República, [2004]. Disponível em: http://www.planalto.gov.br/ccivil_03/constituicao/emendas/emc/emc45.htm. Acesso em: 20 abr. 2020.

CAMPOS, Germán J. Bidart. La interpretación del sistema de derechos humanos. Buenos Aires: Ediar, 1994.

COMISSÃO INTERAMERICANA DE DIREITOS HUMANOS. Convenção Americana sobre Direitos Humanos: assinada na Conferência especializada interamericana sobre direitos humanos, San José, Costa Rica, em 22 de novembro de 1969. Disponível em: https://www.cidh.oas.org/basicos/portugues/c.convencao_americana.htm. Acesso em: 02. abr. 2021.

COMPARATO, Fábio Konder. O papel do juiz na efetivação dos direitos humanos. São Paulo. Disponível em:

https://juslaboris.tst.jus.br/bitstream/handle/20.500.12178/111473/2001_comparato_fabio_pa pel_juiz.pdf?sequence=1\&isAllowed=y. Acesso em: 12.abr.2021.

CONECTAS DIREITOS HUMANOS; CENTRO DE PESQUISA E ESTUDOS DE DIREITO SANITÁRIO. Boletim n.10 direitos humanos na pandemia: mapeamento e análises das normas jurídicas de resposta à covid-19 no Brasil. São Paulo, n. 10, jan 2021. Disponível em: https://cepedisa.org.br/wp-content/uploads/2021/02/Boletim_Direitos-naPandemia_ed_10.pdf. Acesso em: 08. abr.2021.

CONFEDERAÇÃO SINDICAL INTERNACIONAL. Índice Global de los Derechos 2020. Disponível em: https://www.ituc-csi.org/IMG/pdf/ituc_globalrightsindex_2020_es.pdf, Acesso em: 31.out.2020. 
CORTE INTERAMERICANA DE DIREITOS HUMANOS. Caso "A Última Tentação de Cristo" (Olmedo Bustos e outros) versus Chile. Disponível: https://www.cnj.jus.br/wpcontent/uploads/2016/04/f30eb7942e6ea89e4d2ec4ca870784d3.pdf Acesso em: 12.abr.2021.

CORTE INTERAMERICANA DE DIREITOS HUMANOS. Caso Almonacid Arrellano y outros vs. Chile. (considerando n. 124). Disponível em:

https://cidh.oas.org/annualrep/2002port/Chile.12057.htm. Acesso em: 08.set.2020.

CORTE INTERAMERICANA DE DIREITOS HUMANOS. Opinión consultiva OC-1/82 del 24 de setiembre 1982: 'outros tratados' objeto de la función consultiva de la corte (art. 64 convención americana sobre derechos humanos. Solicitada por el Perú. San José, Costa Rica, 1982. Disponível em: https://www.corteidh.or.cr/docs/opiniones/seriea_01_esp1.pdf. Acesso em: 06. abr. 2021.

GIALDINO, Rolando E. Obligaciones del Estado ante el Pacto Internacional de Derechos Económicos, Sociales y Culturales. Disponível in https://www.corteidh.or.cr/tablas/R080663.pdf. Acesso em 01.abr.2021.

MARITAIN, Jacques. Los derechos del hombre y la ley natural. Buenos Aires: Editorial Leviatan, 1982.

MARTINÉZ, Juan Manuel Romero. La protección multinível de los derechos humanos. Tendencias y desafios para la región interamericana. Métodhos, Revista Eletrônica de Investigación Aplicada em Derechos Humanos de la CDHDF, n. 12, janeiro a junho de 2017, p. 36-56. Disponível em: https://revistas-

colaboracion.juridicas.unam.mx/index.php/revista-metodhos/article/view/31868 Acesso em: 10.out.2020.

MAUÉS, Antonio Moreira; MAGALHÃES, Breno Baía. O controle de convencionalidade na América Latina. Rio de Janeiro: Lumen Juris, 2018.

MAZZUOLI, Valerio de Oliveira. Curso de direitos humanos. 3 ed. São Paulo: Método, 2016, p. 218-219.

ONU. Agenda 2030 para o Desenvolvimento Sustentável. Disponível em: http://www.agenda2030.com.br/. Acesso em: 12.nov.2020.

ONU. Pacto Internacional dos Direitos Econômicos, Sociais e Culturais: Adotada pela Resolução n.2.200-A (XXI) da Assembleia Geral das Nações Unidas, em 16 de dezembro de 1966. Disponível em:

https://www.oas.org/dil/port/1966\%20Pacto\%20Internacional\%20sobre\%20os\%20Direitos\% 20Econ\%C3\%B3micos,\%20Sociais\%20e\%20Culturais.pdf. Acesso em: 08. abr.2021.

OST, François Ost; VAN DE KERCHOVE, Michel. De la pirámide a la red?: por una teoría dialéctica del derechos. México, 2008.

PIOVESAN, Flávia. Direitos humanos e o direito constitucional internacional. 14 ed., ver. E atual. São Paulo: Saraiva, 2013.

PIOVESAN, Flávia. Igualdade, diferença e direitos humanos - Perspectivas global e regional. In MALHEIROS, Antonio Carlos; BACARIÇA, Josephina; VALIM, Rafael. Direitos

Humanos. Desafios e perspectivas. Belo Horizonte: Fórum, 2011.

Revista de Direitos Humanos em Perspectiva | e-ISSN: 2526-0197 | Encontro Virtual | v. 7 | n. 1 |

p. 80 - 100 | Jan/Jul. 2021. 
SEVERO, Valdete Souto. A convenção 158 da OIT: os desafios de construir uma cultura jurídica comprometida com os tratados internacionais. Revista da Associação Brasileira de Advogados Trabalhistas, Belo Horizonte, ano 6, p. 259-276, jan/dez 2019.

ZÜÑIGA, Natalia Torres. Control de convencionalidad y protección multinivel de los derechos humanos em el Sistema Interamericano de Derechos Humanos. Revista de la Faculdad de Derecho n. 70, 2013, p. 348-350.

https://www.cidh.oas.org/basicos/portugues/c.convencao_americana.htm 